Article

\title{
The Relationship between Children's Aspiration Profiles and Self-Efficacy, Life Satisfaction, and Academic Achievement
}

\author{
Paolo Bozzato (D) \\ Department of Law, Economics, and Cultures, University of Insubria, 22100 Como, Italy; \\ paolo.bozzato@uninsubria.it
}

Received: 28 March 2020; Accepted: 7 May 2020; Published: 13 May 2020

\begin{abstract}
Limited research in the psychology literature has addressed the specifics of children's future orientations. Using a thematic approach, the present study investigates children's personal aspirations for their adult lives via a questionnaire that addressed (1) the types of aspiration profiles present in a sample of 456 Italian students aged 8-13 and balanced for gender, and (2) how these profiles differ according to demographics, the number of aspirations, academic and social self-efficacy, life satisfaction, and academic achievement. Using cluster analysis, three aspiration profiles emerged, which include individualistic (focused on the possible future self), independent (concentrated on one's own future family and independence), and social (focused on future friends and the family of origin). The independent profile demonstrated better overall psychological and academic adjustment than did the other two profiles. The article discusses the results of the study using the framework of self-determination theory in the context of Italian society.
\end{abstract}

Keywords: children's aspirations; future orientation; self-determination theory

\section{Introduction}

\subsection{Theoretical Framework}

Future orientation is the conscious image that an individual has and self-reports of his or her future. It gives direction and meaning to one's life, providing a foundation for setting life goals (Seginer 2019). Future orientation includes themes of aspirations, intentions, planning, expectations, and goal orientation (Seginer 2009). According to Benson (1994), "These processes are vital to how we organize our current thoughts and behaviors with respect to events which will happen in the future" (p. 376).

Kurt Lewin (1939) was among the first psychologists to treat future orientation as important for regulating present behavior, and he considered one's "psychological future" part of what he called "the life space". He tested his assumptions in experimental designs, studying the influence of an individual's aspiration level on performance; in qualitative research, he studied the effect of future orientation on morale (Lewin [1942] 1948). Following the developmental perspective, Lewin believed human development was characterized by a person's increasing ability to project themselves into the future, and he concentrated his attention on adolescence. In the same historical period, social scientist Frank (1939) studied "time perspective" and introduced two important ideas to the study of future orientation. First, he considered the ideal distance to the future for goal-directed behavior, which should be neither too close nor too distant. Second, he argued that the very first form of future orientation emerged in childhood. In Frank's thinking, development is marked by the progressive acceptance of values and the consideration of the future consequences of one's behavior.

While future orientation has been studied in the context of life span, the majority of future orientation research has been carried out with adolescents because the ability to imagine and organize one's future 
is particularly important in preparing for adulthood (Nurmi 2005). Consequently, different authors have treated future orientation as an essential developmental task in adolescence (e.g., Nurmi 2005; Seginer 2009). However, scholars have paid little attention to children's future orientation (Nurmi 2005).

The construct of future orientation relates to the concept of aspiration, defined by the American Psychological Association's (2015) Dictionary of Psychology as “an ambition, goal, or any kind of desired end that might be achieved through personal effort" (p. 79). In the psychology literature, aspirations have been described as "current concerns" (Klinger 1975), "personal projects" (Little 1983), "life tasks" (Cantor et al. 1987), "personal strivings" (Emmons 1986), "possible selves" (Markus and Nurius 1986), and "personals goals" (Nurmi 2004). In particular, aspirations are similar to goals because goals are essentially future states to be pursued (Dweck 1992). Aspirations differ from expectations because aspirations are the goals someone would like to achieve rather than the goals they expect to achieve. Aspirations are more idealized than expectations and are similar to "hopes" (Nurmi 1987; Seginer et al. 1991; Seginer 2009), meaning they are less realistic than expectations, which are more reasonable assessments of the future.

Aspirations develop across the entire life span. In the psychology literature, adolescence is a milestone in the development of aspirations because it is a period in which individuals reflect much on their future and make adequate choices concerning their future education, occupation, family, hobbies, and the like (Nurmi 2005; Seginer 2009). However, it is worthwhile to study both children's and pre-adolescents' aspirations, which may constitute the roots of adolescents' aspirations. Compared to the aspirations of adolescents, children's aspirations tend to be ambitious and unrealistic (Ginzberg 1952); perhaps for this reason, researchers have not studied them extensively. However, Gottfredson (1981) stated that by around age five children should have overcome magical thinking, allowing them to think more realistically about their future. Subsequent research has shown, first, that older children do not differ fundamentally from adolescents and adults in their ability to distinguish fantasy from reality (Woolley 1997). Second, by around age nine, future orientation is based in reality (Seginer 2009). Several studies using open-ended questions revealed that children's goals tend to be occupational; that is, the subjects mentioned the job or jobs they would like to do as adults rather than reporting desires about other life domains, such as family or hobbies (Auger et al. 2005; Croll et al. 2010). McCallion and Trew (2000) examined the hopes and fears of children aged five to nine and found that, as age increased, the children expressed a greater number of aspirations in both the school and work domains.

In the field of psychology, the development of aspirations has been theorized mainly by vocational psychologists and motivation theorists. Among career development theories, there are a few that give childhood detailed consideration. First, according to Ginzberg et al. (1951), career aspirations begin in early infancy and progressively lead to a series of decisions based on one's interests, abilities, and opportunities. The realism of individuals' occupational aspirations increases when passing from childhood to pre-adolescence and on to adolescence (Ginzberg 1952). Second, according to Havighurst (1964), a typical "developmental task" across childhood and adolescence, in relation to career development, is identification with a worker. Subsequent research confirmed that children identify with adult workers and children's occupational aspirations relate strongly to parent occupations, especially the mother's occupations (Trice and Knapp 1992). Third, Gottfredson $(1981,2002)$ proposed viewing occupational aspirations as an integral part of children's social identity development. The scholar assumed that the development of occupational aspirations comprises four stages. The first three stages deal with processes that occur during childhood, while the fourth stage includes adolescence and adulthood. Each stage implies an increase in cognitive development regarding society and the self, and this is reflected in occupational aspirations. In the first stage ( $3-5$ years of age), children move from a fantasy stage to the "orientation to size and power" when they recognize adults as controllers of resources. They develop an awareness of the fact that they will become adults and take on roles for themselves. In the second stage, "the orientation to sex roles" (6-8 years of age), children's occupational aspirations are consistent with gender stereotypes. For example, they reject occupations associated with the opposite sex. In the third stage, the "orientation to social valuation" (9-13 years of age), they 
evaluate careers on the lifestyle and social status that they could provide. The last stage, which begins at 14 years of age and continues onward, is the "orientation to the self," when individuals select from the remaining options the ones they think are consistent with their personality.

Motivational theories have also considered aspirations. In general, scholars have seen aspirations or personal goals as cognitive representations that have a directional function in motivation (Dweck 1992; Jansen in de Wal et al. 2016; Kolić-Vehovec et al. 2008). Self-determination theory (Deci and Ryan 2000) posits that a full understanding of human motivation involves considering the three innate psychological needs for competence, relatedness, and autonomy. The satisfaction of these needs is considered essential for growth, integrity, and well-being (Deci and Ryan 2000). Kasser and Ryan (1996) distinguished between intrinsic aspirations (e.g., goals such as personal growth, self-esteem, self-efficacy, or community belonging) and extrinsic aspirations (e.g., goals related to wealth, fame, and self-image, which are oriented to obtaining external approval). Intrinsic aspirations are those that one might expect to yield greater basic-need satisfaction (Deci and Ryan 2000). Self-determination theory has been used to interpret research data regarding adolescents' future projects (Marttinen and Salmela-Aro 2012).

In recent decades, a significant body of research has treated goal orientations, or goal profiles or patterns, assuming that individuals have combinations of goals for different tasks, and that some of these combinations are more favorable than others (e.g., Jansen in de Wal et al. 2016; Kolić-Vehovec et al. 2008; Tuominen-Soini et al. 2008). Recent research has shown that children's achievement goal orientations are stable across the transition from primary to middle school (Tuominen et al. 2020). Other researchers have studied the relationship between goal profiles and life satisfaction. However, the literature does not provide a universally agreed-upon definition of life satisfaction, and the term is often used interchangeably with well-being, quality of life, and happiness (Holder and Graydon 2020; Statham and Chase 2010). Multiple studies have suggested that young adults' life satisfaction associates with the type of goals and outcomes they seek to attain. Even if the attempts to investigate the relationship between goal profiles and life satisfaction yielded conflicting results, the goals that address self-improvement and growth (intrinsic aspirations) tend to associate positively with various indices of well-being and adjustment (Tuominen-Soini et al. 2012). Longitudinal (Salmela-Aro and Nurmi 1997) and cross-sectional (Emmons 1991) studies have demonstrated that youths who have goals related to personal relationships, family, and education have better subjective life satisfaction and fewer symptoms of depression than other individuals of the same age do. Moreover, the goals that deal with hobbies and interests associate with high levels of life satisfaction (Little and Chambers 2004).

Research has also investigated the relationship between individuals' aspirations and their outcomes, with the premise that different factors, such as self-efficacy, influence aspirations (Bandura et al. 2001a). The construct of self-efficacy indicates confidence in one's ability to organize and execute the actions needed to solve a problem or accomplish a task (Bandura 1977). Generally speaking, perceived self-efficacy influences academic and occupational aspirations; that is, high levels of self-efficacy beliefs associate with high aspirations. Research also suggests that a high sense of academic self-efficacy promotes both academic aspirations and academic achievements (Bandura et al. 2001a). Studies have reported that social self-efficacy relates directly to academic achievement (Patrick et al. 1997). Bandura et al. (2001a, 2001b) also suggested that social self-efficacy affects academic aspirations, which influence academic achievement. Research has also found that students' high perceived social self-efficacy fosters academic aspirations and well-being, reducing vulnerability to depression (Bandura et al. 2001a, 2001b).

\subsection{Research Questions and Hypotheses of the Study}

Given the scant attention that the psychology literature has paid to the particular contents of children's future orientation (Nurmi 2005), the present study focuses on children's personal aspirations for their adult lives by using a thematic approach to future orientation (Seginer 2009). This study does not deny that adolescence is a fundamental life stage in the development of aspirations, but explores 
children's aspirations, which may subsequently influence future alternatives of choice in various life domains.

The study aimed to answer the following questions: What kind of personal aspirations do children have for their adult lives? How do different aspiration profiles differ by demographics (i.e., gender, age, and urban vs. rural residential area), realism, the number of aspirations, academic and social self-efficacy, life satisfaction, and academic achievements?

In order to answer these questions, the study tested three hypotheses:

Hypothesis 1 (H1). In line with the previous research on goal orientations or profiles, it is highly likely that different profiles of personal aspirations will emerge. The assumption in the present study is that the different goal profiles vary according to the basic psychological needs proposed by the self-determination theory. For example, some profiles only emphasize autonomy (e.g., self, emotions, and lifestyle) or competence (e.g., future education and a job) or relatedness (e.g., social relationships), or two of these basic needs. Other aspiration profiles, instead, consider all the three essential needs of autonomy, competence and relatedness.

Hypothesis 2 (H2). Following the previous literature, the second hypothesis of this study is that the aspiration profiles will not differ with regard to gender, residential area, and realism. Instead, it might be possible to observe an age difference.

Hypothesis 3 (H3). When the three psychological needs proposed by self-determination theory are fully represented in the aspirations, the individuals will have a greater number of goals, higher academic and social self-efficacy, better life satisfaction, and greater academic achievements. On the contrary, the aspiration profiles that do not consider all the three needs of autonomy, competence, and relatedness will associate with poorer psychological and academic adjustment.

\section{Materials and Methods}

\subsection{Participants and Procedures}

The study involved 456 Italian students, 234 males and 222 females (Age $M=10.29 ; S D=1.75$ ), divided into two age groups. The first group included 220 children ( 130 males; 90 females), aged $8-10$ years ( $M=8.63$; $S D=0.71$ ) from four different public primary schools. The second group included 236 pre-adolescents (104 males; 132 females), aged $11-13$ years $(M=11.85 ; S D=0.67)$ from three public middle schools.

The students lived in two different areas of northern Italy: A medium-sized town and a rural area. They completed a self-report questionnaire during regular school days regarding their aspirations for their future adult lives, academic and social self-efficacy, and life satisfaction. Trained testers administered the questionnaire, which took approximately $45 \mathrm{~min}$ to complete in each class. Informed consent was collected before the completion of the questionnaire, both from the pupils and their parents. No student refused to participate. The study was conducted in accordance with the Italian Psychological Association's guidelines on ethics and human subject research.

\subsection{Measures}

\subsubsection{The Revised Version of the Personal Project Inventory}

In the psychology literature, an aspiration is generally interpreted as a unique construct and an individual's aspirations are usually measured by a single question (Rojewski 2007). Thus, the participants completed a revised version of the Personal Project Inventory (Little 1983). They respond to the following open-ended question:

People have different kinds of important goals, projects, and aspirations. These personal goals may include different life areas like school, friends, family, work, studying, dating, health, one's own parents, wealth and the use of money, travelling, the self, or hobbies. How do you see your future as adult? 
The number of aspirations for each subject was counted, and two independent assessors (trained psychologists) performed a content analysis on the answers and compared the results, mediating the disagreements (less than 10\%) through discussions. The categories created based on the material were similar to the ones suggested by and used in previous works (Little 1983; Little and Gee 2007; Marttinen and Salmela-Aro 2012). To ensure that agreements were not due to chance, Choen's Kappa coefficient was computed for each answer category, and $\mathrm{k}$ values were always higher than random patterns $(p<0.01)$. The assessors also rated each personal project in terms of realism, using a 5-point scale. The Spearman's coefficient was used to measure the accordance degree, and the reliability between the two assessors was adequate $\left(\mathrm{r}_{\mathrm{S}}=0.72\right)$.

\subsubsection{Perceived Academic Self-Efficacy Scale}

To assess perceived academic self-efficacy, the present study used a scale that was already available in Italian, and initially developed by Bandura (1993) for use with children. The scale consisted of 19 items that measure children's perceived belief about their success in different curricular subjects (e.g., "How well can you learn mathematics?"), and about their self-regulated learning activities (e.g., "How well can you finish your homework on time?"). Children rated the strength of their beliefs on a 5-point scale ranging from 1 ("Not well at all") to 5 ("Very well"). Following Pastorelli and Picconi (2001), depending on the total raw score, responses were classified based on the individual's level of self-efficacy as very low (18-56 points), low (57-64 points), average (65-70 points), high (71-76 points), or very high (77-95 points). The Italian version of the scale has a level of reliability that complies with the standard criteria of acceptability, with a Cronbach's alpha of 0.86 and a corrected item-total-scale average correlation coefficient of 0.50 (Pastorelli and Picconi 2001). In the current study, Cronbach's alpha was 0.82.

\subsubsection{Perceived Social Self-Efficacy Scale}

The study adopted a scale available in Italian that Bandura (1993) initially developed for use with children. The scale contained 13 items, addressing children's beliefs about their abilities to express personal opinions in groups, share personal experiences with others, and help others in joining one's circle of friends (e.g., "How well can you actively participate in group activities?"). Children rated the strength of their beliefs on a 5-point scale ranging from 1 ("Not well at all") to 5 ("Very well"). Following Pastorelli and Picconi (2001), depending on the total raw score, responses were classified based on the individual's level of self-efficacy as very low (13-48 points), low (49-53, points), average (54-56 points), high (57-59 points), or very high (60-65 points). The Italian version of the scale has satisfactory reliability with a Cronbach's alpha of 0.86 and a corrected item-total-scale average correlation coefficient of 0.53 (Pastorelli and Picconi 2001). In the current study, Cronbach's alpha was 0.79.

\subsubsection{Overall Life Satisfaction}

Using a single-item measure, children and pre-adolescents reported how satisfied they were with their life as a whole. A 5-point scale was used for pre-adolescents (11-13 years old), ranging from 0 (not at all satisfied) to 5 (totally satisfied) and a 5-point emoticon scale, ranging from a very unhappy face to a very happy face, was employed with children aged 8-10. The Overall Life Satisfaction is the most widely used measure of subjective well-being (Rees et al. 2013; Tomyn and Cummins 2011) and studies have provided consistent evidence of validity and reliability of a single-item measure of life satisfaction (e.g., Cheung and Lucas 2014).

\subsubsection{Academic Achievement}

The mean midyear scores of students in the three main courses (Italian language, mathematics, and English language) served as a proxy for assessing each child's academic achievement. Teachers who had access to the students' records provided this information. In Italian schools, the possible grades range from 0 to 10 , with 6 being the lowest passing grade and 10 the highest passing grade. 


\subsection{Analysis Plan}

The dataset contained dichotomous variables; therefore, hierarchical cluster analysis was conducted using average linkage method and the Jaccard similarity index as similarity measure, suitable for binary data (Gore 2000). All quantitative analyses were performed using the SPSS Statistics 26.0 software (IBM Corporation 2019). The hierarchical cluster analysis technique was appropriate, giving the lack of a precise hypothesis about the number of groups that could emerge from the data.

A series of one-way analyses of variance (ANOVAs) was also performed to compare groups with different profiles concerning other variables, such as self-efficacy, life satisfaction, education outcomes, and aspirational realism. In case of a violation of the underlying assumptions of an ANOVA, the Welch and Kruskal-Wallis tests were performed. The effect size was analyzed using partial eta squared $\left(\eta^{2}\right)$. The Bonferroni test, with $p<0.005$, was employed for the ANOVAs post hoc comparisons because this test reduces the risk of Type I error.

\section{Results}

\subsection{Personal Aspirations: Descriptive Statistics and Clusters}

The first aim of the study was to determine the range and content of profiles based on children's aspirations. On the whole, the children and pre-adolescents mentioned 1800 goals. The number of aspirations written by each student ranged from 1 to $12(M=3.95 ; S D=2.35)$. The goals mentioned by the participants were content-analyzed into 14 different classes. The work domain was cited by $98.7 \%$ of the sample's subjects. The categories and examples of responses are presented in Table 1.

Table 1. Aspiration categories, examples, and descriptive statistics.

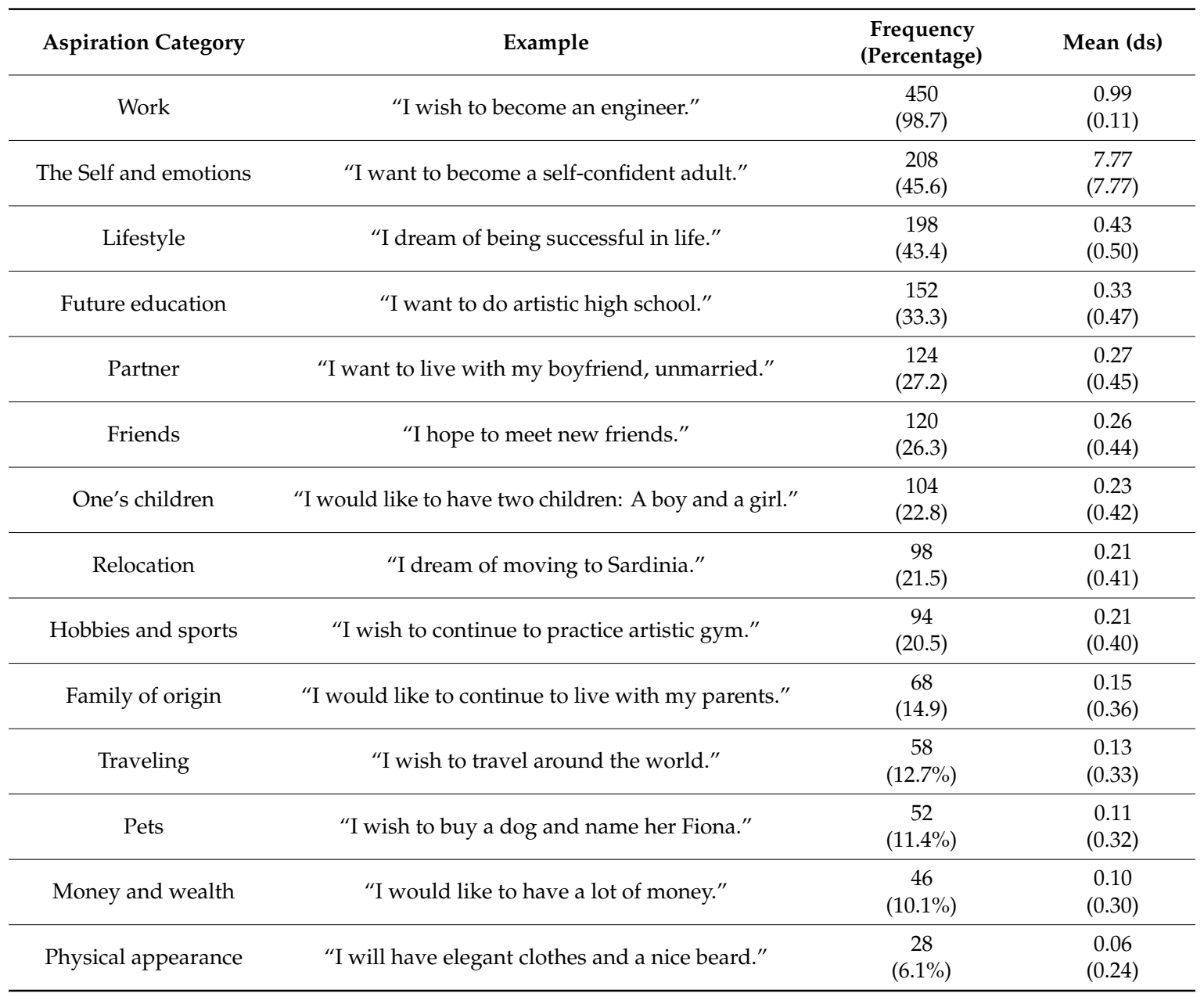


The results of the cluster analysis showed three cluster solutions; the three aspiration profiles groups were labeled as individualistic, independent, or social. Cluster $1(n=310)$, the "individualistic profile," included $68 \%$ of the subjects. Cluster 1 subjects produced a small number of aspirations $(M=2.97)$ and, in almost half of the cases, the adult life goals related to the self and emotions, and the future lifestyle (e.g., "I want to be famous," "I want to live in a large house," and "I want to drive a sports car and spend weekends out of town"). In one-third of the cases, aspirations were concerned with future education, and only very few mentioned friends and romantic partners. None of the participants wrote about wanting to become a parent.

Cluster 2 ( $n=114)$, consisting of $25 \%$ of the sample and labeled the "independent profile," generated the largest number of aspirations $(M=6.91)$. This cluster included nearly of all the subjects who wrote about wanting to have their own family (citing both children and pets), and an independent life. The personal goals in this cluster related primarily to the individuals themselves and their emotions, lifestyle, future education, relocation, and friends.

Cluster $3(n=32)$, the "social profile," included $7 \%$ of the subjects. The children and pre-adolescents of this cluster were characterized by a small number of aspirations $(M=2.94)$, and did not have any goals regarding future education, having one's own family, or desired physical appearance. Very few were concerned with their self and emotions. These subjects mainly produced hopes and dreams regarding friends and the family of origin.

Table 2 reports the frequencies and percentages of the three clusters for each aspiration category.

Table 2. The frequencies and percentages of the three clusters for each aspiration category.

\begin{tabular}{|c|c|c|c|c|}
\hline \multirow[b]{2}{*}{ Aspiration Category } & \multicolumn{3}{|c|}{ Clusters } & \multirow{2}{*}{$\begin{array}{l}\text { Total Sample } \\
\quad(N=456)\end{array}$} \\
\hline & $\begin{array}{l}\text { Individualistic Profile } \\
\qquad(\mathrm{N}=310)\end{array}$ & $\begin{array}{l}\text { Independent Profile } \\
\qquad(\mathrm{N}=114)\end{array}$ & $\begin{array}{l}\text { Social Profile } \\
\qquad(\mathrm{N}=32)\end{array}$ & \\
\hline Work & $\begin{array}{c}306 \\
(98.7 \%)\end{array}$ & $\begin{array}{c}112 \\
(98.2 \%)\end{array}$ & $\begin{array}{c}32 \\
(100 \%)\end{array}$ & $\begin{array}{c}450 \\
(98.7 \%)\end{array}$ \\
\hline The Self and emotions & $\begin{array}{c}138 \\
(44.5 \%)\end{array}$ & $\begin{array}{c}68 \\
(59.6 \%)\end{array}$ & $\begin{array}{c}2 \\
(6.3 \%)\end{array}$ & $\begin{array}{c}208 \\
(45.6 \%)\end{array}$ \\
\hline Lifestyle & $\begin{array}{c}124 \\
(40 \%)\end{array}$ & $\begin{array}{c}70 \\
(61.4 \%)\end{array}$ & $\begin{array}{c}4 \\
(12.5 \%)\end{array}$ & $\begin{array}{c}198 \\
(43.4 \%)\end{array}$ \\
\hline Future education & $\begin{array}{c}108 \\
(34.8 \%)\end{array}$ & $\begin{array}{c}44 \\
(38.6 \%)\end{array}$ & $\begin{array}{c}0 \\
(0)\end{array}$ & $\begin{array}{c}152 \\
(33.3 \%)\end{array}$ \\
\hline Partner & $\begin{array}{c}10 \\
(3.2 \%)\end{array}$ & $\begin{array}{c}114 \\
(100 \%)\end{array}$ & $\begin{array}{c}0 \\
(0)\end{array}$ & $\begin{array}{c}124 \\
(27.2 \%)\end{array}$ \\
\hline Friends & $\begin{array}{c}36 \\
(11.6 \%)\end{array}$ & $\begin{array}{c}64 \\
(56.1 \%)\end{array}$ & $\begin{array}{c}20 \\
(62.5 \%)\end{array}$ & $\begin{array}{c}120 \\
(26.3 \%)\end{array}$ \\
\hline One's children & $\begin{array}{c}0 \\
(0)\end{array}$ & $\begin{array}{c}104 \\
(91.2 \%)\end{array}$ & $\begin{array}{c}0 \\
(0)\end{array}$ & $\begin{array}{c}104 \\
(22.8 \%)\end{array}$ \\
\hline Relocation & $\begin{array}{c}32 \\
(10.3 \%)\end{array}$ & $\begin{array}{c}62 \\
(54.4 \%)\end{array}$ & $\begin{array}{c}4 \\
(12.5 \%)\end{array}$ & $\begin{array}{c}98 \\
(21.5)\end{array}$ \\
\hline Hobbies and sports & $\begin{array}{c}56 \\
(18.1 \%)\end{array}$ & $\begin{array}{c}34 \\
(29.8 \%)\end{array}$ & $\begin{array}{c}4 \\
(12.5 \%)\end{array}$ & $\begin{array}{c}94 \\
(20.6 \%)\end{array}$ \\
\hline Family of origin & $\begin{array}{c}34 \\
(11 \%)\end{array}$ & $\begin{array}{c}14 \\
(12.3 \%)\end{array}$ & $\begin{array}{c}20 \\
(62.5 \%)\end{array}$ & $\begin{array}{c}68 \\
(14.9 \%)\end{array}$ \\
\hline Traveling & $\begin{array}{c}34 \\
(11 \%)\end{array}$ & $\begin{array}{c}22 \\
(19.3 \%)\end{array}$ & $\begin{array}{c}2 \\
(6.3 \%)\end{array}$ & $\begin{array}{c}58 \\
(12.7 \%)\end{array}$ \\
\hline Pets & $\begin{array}{c}12 \\
(3.9 \%)\end{array}$ & $\begin{array}{c}38 \\
(33.3 \%)\end{array}$ & $\begin{array}{c}2 \\
(6.3 \%)\end{array}$ & $\begin{array}{c}52 \\
(11.4 \%)\end{array}$ \\
\hline Money and wealth & $\begin{array}{c}14 \\
(4.5 \%)\end{array}$ & $\begin{array}{c}28 \\
(24.6 \%)\end{array}$ & $\begin{array}{c}4 \\
(12.5 \%)\end{array}$ & $\begin{array}{c}46 \\
(10.1 \%)\end{array}$ \\
\hline Physical appearance & $\begin{array}{c}14 \\
(4.5 \%)\end{array}$ & $\begin{array}{c}14 \\
(12.3 \%)\end{array}$ & $\begin{array}{c}0 \\
(0)\end{array}$ & $\begin{array}{c}28 \\
(6.1 \%)\end{array}$ \\
\hline
\end{tabular}




\subsection{Preliminary Analyses}

A chi-square test was performed to explore the possible age-group difference in cluster membership. The results revealed a statistical difference in terms of the individualistic profile being prevalent among the middle school students, and the independent and social profiles being prevalent in the primary school students $\left(\chi^{2}(2)=18.76, p<0.001\right)$. A one-way ANOVA, using age as continuous variable, confirmed the age difference among the three aspiration profiles $\left(\mathrm{F}_{2,453}=9.22, p<0.001, \eta^{2}=0.04\right)$. Post hoc tests (Bonferroni, $p<0.005$ ) showed that the individualistic profile was composed of older students (age $M=10.52 ; S D=1.77$ ) than the independent profile (age $M=9.89 ; S D=1.60$ ) and the social profile (age $M=9.50 ; S D=1.68$ ), while the independent and social profiles did not differ significantly in terms of age.

Cluster membership was neither associated with gender $\left(\chi^{2}(2)=3.35, p=0.19\right.$ n.s. $)$ nor with residential location when comparing urban and rural $\left(\chi^{2}(2)=0.41, p=0.82\right.$ n.s. $)$.

A one-way ANOVA was carried out to verify whether the three profile groups differed regarding the number of aspirations mentioned. The assumption of the homogeneity of variance was not met for these data; Welch's adjusted $F$ ratio $\left(F_{106,791}=196.26\right)$ was significant with $p<0.001, \eta^{2}=0.53$. Post hoc tests showed that the independent profile mentioned a larger number of aspirations $(M=6.91$; $S D=1.98)$ than the individualistic profile $(M=2.97 ; S D=1.53)$ and the social profile $(M=2.94$; $S D=0.76)$. Instead, the individualistic and the social profiles did not differ regarding the number of aspirations.

The majority of the aspirations (66.7\%) were evaluated with a medium or high level of realism, while 33.3\% had a low realism (for example, "I want to decorate urban walls for a living" or "I will be a famous actress"). The realism score mean was $3.22(S D=1.47)$. The Kruskal-Wallis test verified whether the three profiles differed in terms of realism, but no statistical differences were found: $\mathrm{U}(N=456)=0.14, p=0.93$ n.s.

\subsection{Differences in Academic and Social Self-Efficacy}

A one-way ANOVA was carried out with personal aspiration profiles as the independent variable and with, first, academic self-efficacy and, then, social self-efficacy as the dependent variable. Clusters had statistically significant differences, both regarding academic $\left(F_{2,453}=13.38 ; p<0.001, \eta^{2}=0.06\right)$ and social self-efficacy $\left(\mathrm{F}_{2,453}=31.21 ; p<0.001, \eta^{2}=0.12\right)$.

Post hoc comparisons revealed a higher mean score in the academic self-efficacy for the independent profile $(M=3.34 ; S D=0.98)$ when compared to the individualistic profile $(M=2.97 ; S D=0.91)$ and the social profile $(M=2.44 ; S D=1.02)$. These last two profiles were not significantly different.

Regarding social self-efficacy, post hoc tests showed that the social profile had the highest mean score $(M=3.47 ; S D=0.84)$, but it did not show statistically significant differences in relation to the independent profile $(M=3.08 ; S D=0.91)$. Both the independent and social profiles differed significantly from the individualistic profile $(M=2.49 ; S D=0.87)$, which had the lowest mean score.

\subsection{Differences in Life Satisfaction}

A one-way ANOVA performed with personal aspiration profiles as the independent variable and with overall life satisfaction as the dependent variable showed that the three aspiration profiles had statistically significant differences $\left(\mathrm{F}_{2,453}=12.85 ; p<0.001, \eta^{2}=0.5\right)$. While the independent profile had the highest mean score in overall life satisfaction $(M=3.17 ; S D=0.99)$, it exhibited a statistically significant difference only in relation to the individualistic profile $(M=2.67 ; S D=0.86)$, but not in relation to the social profile $(M=3.03 ; S D=1.18)$. These last two aspiration profiles did not differ from one another in this dimension. 


\subsection{Differences in Academic Achievement}

To test the statistical differences among the three profiles in academic achievement, a one-way ANOVA was employed with personal aspiration profiles as the independent variable and with academic achievement as the dependent variable. The results showed that the three profiles had statistically significant differences $\left(F_{2,453}=7.60 ; p<0.001, \eta^{2}=0.03\right)$. In this case, the independent profile had a higher mean score in the academic achievement $(M=6.56 ; S D=0.11)$ than both the individualistic $(M=6.13 ; S D=1.14)$ and the social $(M=5.84 ; S D=1.02)$ profiles. These last two profiles did not differ significantly from one another.

\section{Discussion}

The first purpose of this study was to identify what kind of personal aspirations children and pre-adolescents have for their adult lives. The three patterns of aspirations that emerged after cluster analysis included an individualistic profile ( $68 \%$ of the sample), an independent profile $(25 \%)$, and a social profile $(7 \%)$. These profiles differed regarding the basic psychological needs proposed by self-determination theory, meaning that the results support Hypothesis 1 . Work was the only type of aspiration that was prevalent across all three profiles, making it more of a constant than a variable. This result is consistent with previous studies showing that a profession is a dominant aspect of children's sense of the future (e.g., Croll et al. 2010).

The individualistic profile had limited aspirations and primarily addressed to oneself and one's emotions, future education, and lifestyle, without considering much in the area of social relationships. This profile was prevalent among the pre-adolescents, likely because when entering the adolescence stage, these individuals concentrated more on developing oneself than younger children do. Being this the profile group containing the most individuals, it may also reflect the individualistic tendencies of Italian society. According to Hoftede et al. (2010) societies can be described based on the degree of individualism or collectivism. Italy, particularly the northern part of the country, where the participants lived, has a high level of individualism according to the authors' research. National statistical data show that one-third of Italian families in 2019 comprised a single person (ISTAT 2019). The notion of a family no longer carries the assumption of a group as in the past, and so-called nuclear families-those with two parents and typically only one or two children-are now the most widespread. According to Hoftede et al. (2010),

“Children from such families, as they grow up, soon learn to think of themselves as 'I.' This 'I,' their personal identity, is distinct from other people's 'I's, and these others are classified not according to their group membership but instead according to individual characteristics".

(p. 91)

As the results of this study suggest, this way of thinking may influence children's aspirations for their future. From the perspective of self-determination theory, this profile emphasized the needs of autonomy and competence, but not of relatedness.

The independent profile consisted of $25 \%$ of the sample and produced the highest number of aspirations. The participants belonging to this profile aspired to become independent from their families of origin and desired their own families with a partner; in most cases, they also wanted to have children and, in some cases, pets. Many of them imagine themselves having some friends, and they also think of themselves and their emotions, lifestyle, and future education. This aspiration profile was the only one that included all three psychological needs of autonomy, competence, and relatedness.

The social profile was the least common, representing only $7 \%$ of participants, and produced a low number of aspirations. The children and pre-adolescents belonging to this profile focused on their friends and families of origin, but did not concentrate much on themselves and their emotions, and thought little if at all about their future education and families. According to the self-determination theory, this orientation emphasized the need for relatedness. 
The second purpose of this study was to identify the possible differences among the three aspiration profiles regarding the demographic variables, realism, the number of aspirations, academic and social self-efficacy, life satisfaction, and academic achievements. As postulated by Hypothesis 2 , the three aspiration profiles did not differ in terms of gender and residential area (urban vs. rural), the only difference related to age. The individualistic profile was most prevalent among the middle school students, while membership in the other two profile groups was more common among the primary school pupils. It seems that as children mature, they are influenced by the individualistic society to which they belong; consequently, their aspirations focus on individualistic matters. The pre-adolescents' aspirations were not more realistic that those of younger children, a result that is consistent with previous research on career thinking (e.g., Auger et al. 2005).

As assumed by Hypothesis 3, aspiration profiles that incorporated the three psychological needs of autonomy, competence, and relatedness related to better psychological and academic adjustment. However, the picture that emerged is complex. First, the independent profile produced the highest number of aspirations, suggesting that this group was comprised of the most active individuals in terms of future-oriented thinking (i.e., reflecting more on the future than children in the other two profiles). Second, the independent profile demonstrated the highest academic self-efficacy score, but the social profile had the highest social self-efficacy score. However, the social profile did not differ in a statistically significant way from the independent profile. Therefore, it can be concluded that the highest social self-efficacy beliefs belonged to the independent and social profiles, but not to the individualistic profile. Third, the independent profile had the highest academic achievement, and the difference with the other profiles was statistically significant. Finally, regarding overall life satisfaction, the independent profile was that of the most satisfied children and pre-adolescents. However, the difference was statistically significant only in relation to the individualistic profile, meaning that the individuals with independent and social profiles had a higher level of perceived well-being than those with the individualistic profile. These results align with previous studies on older students that have reported that youths with goals related to personal relationships, family, and education have better subjective life satisfaction (Emmons 1991; Salmela-Aro and Nurmi 1997).

\section{Conclusions}

Subjects with an independent profile were the only participants whose aspirations fully represented the basic needs proposed by the self-determination theory; this group also showed better general psychological and academic adjustment than those with other aspiration profiles. The three needs for competence (e.g., future education and a job), autonomy (independence from the family of origin), and relatedness (e.g., a partner, own children, friends) were all represented in the goals of the independent profile. Regarding the other two profiles, the lack of aspirations concerning the social aspects (as in the individualistic profile) or autonomy (as in the social profile) is connected to a generally low adjustment.

Some methodological limitations of the present study should be noted. First, participants were recruited as a convenience sample, so the extent to which the present sample represents its respective population is unknown. Thus, caution is needed when generalizing the findings of the present study. Second, this study relied on children's and pre-adolescents' self-reports (except for academic achievement). There was no external verification of these reports, which may have been affected by recall and social desirability bias. Third, social profile group only included 32 individuals, which influenced the statistical comparisons. Literature suggests that a sample of at least 30 units is sufficient for the statistical analyses performed in the study (Howell 2011). Finally, the causal relationships among the various psychological factors could not be empirically tested using the cross-sectional design of the present study. Future research on children's aspirations should use longitudinal studies and should employ other statistical techniques besides cluster analysis, such as latent profile analysis (Pastor et al. 2007), to examine goal profiles. Future research should also explore how the perceived or actual educational environment interacts with personal dispositions in shaping children's aspirations. 
Despite the above limitations, the results of this explorative study provide pertinent information for understanding children's aspiration patterns for their adult lives in the context of contemporary Italian society.

School education should assist students in preparing for their future. Therefore, these results could be useful for teachers and educators who want to address future orientation issues with their students. For example, educators should be aware that not all the students have the same type of "future thinking" in terms of the number and type of life domains they consider. Thus, teachers could plan educational activities to improve students' "future thinking" skills on a broad spectrum of life domains to balance the prevalent tendency among children to produce aspirations mainly related to the work domain. Educators could also help children and pre-adolescents to understand their needs as human beings and to imagine an adult's important needs, and to project a future based on those needs. Then, teachers and educators could identify students with low academic achievement, low self-efficacy beliefs, and low life satisfaction to support them, mainly in the task of expressing their aspirations and designing their futures.

Funding: This research received no external funding.

Conflicts of Interest: The author declares no conflict of interest.

\section{References}

American Psychological Association. 2015. APA Dictionary of Psychology, 2nd ed. Edited by Gary R. VandenBos. Washington, DC: American Psychological Association. [CrossRef]

Auger, Richard W., Anne E. Blackhurst, and Kay Herting Wahl. 2005. The development of elementary-aged children's career aspirations and expectations. Professional School Counselling 8: 322-29.

Bandura, Albert. 1977. Self-efficacy: Toward a unifying theory of behavioral change. Psychological Review 84: 191-205. [CrossRef] [PubMed]

Bandura, Albert. 1993. Perceived self-efficacy in cognitive development and functioning. Educational Psychology 28: 117-48. [CrossRef]

Bandura, Albert, Claudio Barbaranelli, Gian Vittorio Caprara, and Concetta Pastorelli. 2001a. Self-efficacy beliefs as shapers of children's aspirations and career trajectories. Child Development 72: 187-206. [CrossRef] [PubMed]

Bandura, Albert, Gian Vittorio Caprara, Claudio Barbaranelli, Concetta Pastorelli, and Camillo Regalia. 2001b. Sociocognitive self-regulatory mechanisms governing transgressive behavior. Journal of Personality and Social Psychology 80: 125-35. [CrossRef]

Benson, Janette B. 1994. The origins of future orientation in the everyday life of 9- to 36-month-old infants. In The Development of Future-Oriented Processes. Edited by Marshall M. Haith, Janette B. Benson, Ralph J. Roberts Jr. and Bruce F. Pennington. Chicago: University of Chicago Press, pp. 375-407.

Cantor, Nancy, Julie Norem, Christopher Langston, Sabrina Zirkel, William Fleeson, and Carol Cook-Flannagan. 1987. Life tasks and daily life experience. Journal of Personality 59: 425-51. [CrossRef]

Cheung, Felix, and Richard E. Lucas. 2014. Assessing the validity of single-item life satisfaction measures: Results from three large samples. Quality of Life Research 23: 2809-18. [CrossRef]

Croll, Paul, Gaynor Attwood, and Carol Fuller. 2010. Children's Lives, Children's Future. London: Continuum.

Deci, Edward L., and Richard Ryan. 2000. The "what" and "why" of goal pursuits: Human needs and the self-determination of behavior. Psychological Inquiry 11: 227-68. [CrossRef]

Dweck, Carol. 1992. Commentary: The Study of Goals in Psychology. Psychological Science 3: 165-67. [CrossRef]

Emmons, Robert A. 1986. Personal strivings: An approach to personality and subjective wellbeing. Journal of Personality and Social Psychology 51: 1058-68. [CrossRef]

Emmons, Robert A. 1991. Personal strivings, daily life events and psychological and physical wellbeing. Journal of Personality 59: 453-72. [CrossRef] [PubMed]

Frank, Lawrence K. 1939. Time perspectives. Journal of Social Philosophy 4: 293-312.

Ginzberg, Eli. 1952. Toward a theory of occupational choice. Occupations 30: 491-94. [CrossRef] 
Ginzberg, Eli, Sol W. Ginsburg, Sidney Axelrad, and John L. Herma. 1951. Occupational Choice: An Approach to a General Theory. New York: Columbia University.

Gore, Paul A. 2000. Cluster analysis. In Handbook of Applied Multivariate Statistics and Mathematical Modelling. Edited by Howard E. A. Tinsley and Steven D. Brown. San Diego: Academic Press, pp. 297-321.

Gottfredson, Linda S. 1981. Circumscription and compromise: A developmental theory of occupational aspirations. Journal of Counseling Psychology 28: 545-79. [CrossRef]

Gottfredson, Linda S. 2002. Gottfredson's theory of circumscription, compromise, and self-creation. In Career Choice and Development. Edited by Duane Brown. San Francisco: Jossey-Bass, pp. 85-148.

Havighurst, Robert J. 1964. Youth in exploration and man emergent. In Man in a World of Work. Edited by Henry Horow. Boston: Houghton Mifflin, pp. 215-36.

Hoftede, Geert, Gert Jan Hofstede, and Michael Minkov. 2010. Culture and Organizations: Software of the Mind. Intercultural Cooperation and Its Importance for Survival, 3rd ed. New York: McGraw Hill.

Holder, Mark D., and Katherine Graydon. 2020. Positive Well-Being. In The Encyclopedia of Child and Adolescent Development. Edited by Stephen Hupp and Jeremy D. Jewell. Hoboken: Wiley, pp. 1-11. [CrossRef]

Howell, David C. 2011. Statistical Methods for Psychology, 8th ed. Belmont: Wadsworth.

IBM Corporation. 2019. IBM SPSS Statistics. version 26.0. Macintosh. Armonk: IBM Corporation.

ISTAT. 2019. Annuario Statistico Italiano 2019. Roma: ISTAT.

Jansen in de Wal, Joost, Lisette Hornstra, Frans J. Prins, Thea Peetsma, and Ineke Van Der Veen. 2016. The prevalence, development and domain specificity of elementary school students' achievement goal profiles. Educational Psychology 36: 1303-22. [CrossRef]

Kasser, Tim, and Richard Ryan. 1996. Further Examining the American Dream: Differential Correlates of Intrinsic and Extrinsic Goals. Personality and Social Psychology Bulletin 22: 280-87. [CrossRef]

Klinger, Eric. 1975. Consequences of commitment to and disengagement from incentives. Psychological Review 82: 223-31. [CrossRef]

Kolić-Vehovec, Svjetlana, Barbara Rončević, and Igor Bajšanski. 2008. Motivational components of self-regulated learning and reading strategy use in university students: The role of goal orientation patterns. Learning and Individual Differences 18: 108-13. [CrossRef]

Lewin, Kurt. 1948. Time perspective and morale. In Resolving Social Conflict. Edited by Kurt Lewin. New York: Harper \& Brothers, pp. 103-24. First published 1942.

Lewin, Kurt. 1939. Field theory and experiment in social psychology. American Journal of Sociology 44: 868-96. [CrossRef]

Little, Brian R. 1983. Personal projects: A rationale and method for investigation. Environment E Behavior 15: 273-309. [CrossRef]

Little, Brian R., and Neil C. Chambers. 2004. Personal project pursuit: On human doings and well-beings. In Handbook of Motivational Counseling: Concepts, Approaches, and Assessment. Edited by W. Miles Cox and Eric Klinger. Chichester: Wiley, pp. 65-82. [CrossRef]

Little, Brian R., and Travis L. Gee. 2007. The Methodology of Personal Projects Analysis: Four Modules and a Funnel. In Personal Project Pursuit. Goals, Action, and Human Flourishing. Edited by Brian R. Little, Katariina Salmela-Aro and Susan D. Phillips. New York: Psychology Press, pp. 51-94. [CrossRef]

Markus, Hazel, and Paula Nurius. 1986. Possible Selves. American Psychologist 41: 954-69. [CrossRef]

Marttinen, Elina, and Katariina Salmela-Aro. 2012. Personal goal orientations and subjective well-being of adolescents. Japanese Psychological Research 54: 262-73. [CrossRef]

McCallion, Amanda, and Karen Trew. 2000. A longitudinal study of children's hopes, aspirations and fears for the future. The Irish Journal of Psychology 21: 227-36. [CrossRef]

Nurmi, Jari-Erik. 1987. Age, Sex, Social Class, and Quality of Family Interaction as Determinants of Adolescents' Future Orientation: A Developmental Task Interpretation. Adolescence 22: 977-91. [PubMed]

Nurmi, Jari-Erik. 2004. Socialization and self-development: Channeling, selection, adjustment, and reflection. In Handbook of Adolescent Psychology, 2nd ed. Edited by Richard Lerner and Laurence Steinberg. Hoboken: Wiley, pp. 85-124.

Nurmi, Jari-Erik. 2005. Thinking About and Acting Upon the Future: Development of Future Orientation Across the Life Span. In Understanding Behavior in the Context of Time. Theory, Research, and Application. Edited by Alan Strathman and Jeff Joireman. Mahwah: Erlbaum, pp. 31-57. 
Pastor, Dena A., Kenneth E. Barron, B. J. Miller, and Susan L. Davis. 2007. A latent profile analysis of college students' achievement goal orientation. Contemporary Educational Psychology 32: 8-47. [CrossRef]

Pastorelli, Concetta, and Laura Picconi. 2001. Academic, social and self-regulatory self-efficacy. In Self-Efficacy Assessment. Edited by Gian Vittorio Caprara. Trento: Erickson, pp. 87-104.

Patrick, Helen, Lynley Hicks, and Allison M. Ryan. 1997. Relations of perceived social efficacy and social goal pursuit to self-efficacy for academic work. Journal of Early Adolescence 17: 109-28. [CrossRef]

Rees, Gwyther, Haridhan Goswami, Larissa Pople, Jonathan Bradshaw, Antonia Keung, and Gill Main. 2013. The Good Childhood Report 2013. London: The Children's Society.

Rojewski, Jay W. 2007. Occupational and educational aspirations. In Career Development in Childhood and Adolescence. Edited by Vladimir B. Skorikov and Wendy Patton. Rotterdam: Sense Publishers, pp. 87-104.

Salmela-Aro, Katariina, and Jari-Erik Nurmi. 1997. Goal contents, well-being, and life context during transition to university: A longitudinal study. International Journal of Behavioral Development 20: 471-91. [CrossRef]

Seginer, Rachel. 2009. Future Orientation: Developmental and Ecological Perspectives. Boston: Springer.

Seginer, Rachel. 2019. Adolescent Future Orientation: Does Culture Matter? Online Readings in Psychology and Culture 6. [CrossRef]

Seginer, Rachel, Jari-Erik Nurmi, and M. Poole. 1991. Adolescents' future orientation in cross-cultural perspectives. Paper presented at the 11th Meeting of the International Society for the Study of Behavioral Development, Minneapolis, MN, USA, July 1-2.

Statham, June, and Elaine Chase. 2010. Childhood Wellbeing: A Brief Overview. Loughborough: Childhood Wellbeing Research Centre.

Tomyn, Adrian J., and Robert A. Cummins. 2011. Subjective wellbeing and homeostatically protected mood: Theory validation with adolescents. Journal of Happiness Studies: An Interdisciplinary Forum on Subjective Well-Being 12: 897-914. [CrossRef]

Trice, Ashton D., and Linda Knapp. 1992. Relationship of children's career aspiration to parent's occupations. Journal of Genetic Psychology 153: 355-57. [CrossRef]

Tuominen, Heta, Markku Niemivirta, Kirsti Lonka, and Katariina Salmela-Aro. 2020. Motivation across a transition: Changes in achievement goal orientations and academic well-being from elementary to secondary school. Learning and Individual Differences 79: 1-15. [CrossRef]

Tuominen-Soini, Heta, Katariina Salmela-Aro, and Markku Niemivirta. 2008. Achievement goal orientations and subjective well-being: A person-centred analysis. Learning and Instruction 18: 251-66. [CrossRef]

Tuominen-Soini, Heta, Katariina Salmela-Aro, and Markku Niemivirta. 2012. Achievement goal orientations and academic well-being across the transition to upper secondary education. Learning and Individual Differences 22: 290-305. [CrossRef]

Woolley, Jacqueline D. 1997. Thinking about Fantasy: Are Children Fundamentally Different Thinkers and Believers from Adults? Child Development 68: 991-1011. [CrossRef] [PubMed]

(C) 2020 by the author. Licensee MDPI, Basel, Switzerland. This article is an open access article distributed under the terms and conditions of the Creative Commons Attribution (CC BY) license (http://creativecommons.org/licenses/by/4.0/). 